\title{
Internet pornography viewing preference as a risk factor for adolescent Internet addiction: The moderating role of classroom personality factors
}

\author{
KYRIAKI ALEXANDRAKI ${ }^{1,2}$, VASILEIOS STAVROPOULOS ${ }^{2,3 *}$, TYRONE L. BURLEIGH ${ }^{3 *}$, DANIEL L. KING \\ and MARK D. GRIFFITHS ${ }^{5}$ \\ ${ }^{1}$ Specialized Unit for Assessment and Treatment of Sexual Offenders, Department of Justice, Victorian Government \\ Australia, Melbourne, VIC, Australia \\ ${ }^{2}$ School of Psychology, National and Kapodistrian University of Athens, Athens, Greece \\ ${ }^{3}$ Faculty of Health, Federation University, Mount Helen, VIC, Australia \\ ${ }^{4}$ School of Psychology, University of Adelaide, Adelaide, SA, Australia \\ ${ }^{5}$ International Gaming Research Unit, Nottingham Trent University, Nottingham, UK
}

(Received: September 21, 2017; revised manuscript received: March 29, 2018; accepted: March 30, 2018)

\begin{abstract}
Background and aims: Adolescent Internet pornography viewing has been significantly increased in the last decade with research highlighting its association with Internet addiction (IA). However, there is little longitudinal data on this topic, particularly in relation to peer context effects. This study aimed to examine age- and context-related variations in the Internet pornography-IA association. Methods: A total of 648 adolescents, from 34 classrooms, were assessed at 16 years and then at 18 years to examine the effect of Internet pornography preference on IA in relation to the classroom context. IA was assessed using the Internet Addiction Test (Young, 1998), Internet pornography preference (over other Internet applications) was assessed with a binary (yes/no) question, and classroom introversion and openness to experience (OTE) with the synonymous subscales within the Five Factor Questionnaire (Asendorpf \& Van Aken, 2003). Results: Three-level hierarchical linear models were calculated. Findings showed that viewing Internet pornography exacerbates the risk of IA over time, while classroom factors, such as the average level of OTE and introversion, differentially moderate this relationship. Discussion and conclusion: The study demonstrated that the contribution of Internet pornography preference (as an IA risk factor) might be increased in more extroverted classrooms and decreased in OTE classrooms.
\end{abstract}

Keywords: Internet, pornography, Internet addiction, classroom, openness to experience, introversion

\section{INTRODUCTION}

Internet pornography viewing (IPV) has been defined as the online viewing or downloading of pictures and videos with clearly exposed genitals and/or pictures or videos in which people are having sex (with the intention of eliciting a sexual reaction; Peter \& Valkenburg, 2009). The prevalence of IPV has increased dramatically, partly attributed to the availability of such online material (Koletić, 2017; Owens, Behun, Manning, \& Reid, 2012; Peter \& Valkenburg, 2006; Reiner et al., 2017; Wolak, Mitchell, \& Finkelhor, 2007; Ybarra \& Mitchell, 2005) with one in two adolescents actively seek out sexual content in their media choices (Bleakley, Hennessy, \& Fishbein, 2011). Although adolescent IPV is considered to some extent a normative behavior (Anderson, Steen, \& Stavropoulos, 2016; Koletić, 2017), excessive and early use of pornographic material is known to compromise adolescents' well-being (Mattebo, Tydén, Häggström-Nordin, Nilsson, \& Larsson, 2013; Mesch, 2009; Owens et al., 2012; Tsitsika et al., 2009) and may trigger Internet Addiction (IA) behaviors (Anderson et al., 2016; Koletić, 2017). Given the significant impact that IA can have upon an individual (e.g., increased irritability, interpersonal sensitivity, impulsiveness and aggression, poor social functioning, and social anxiety; Kuss \& Lopez-Fernandez, 2016), and to contribute to understanding the risk factors for IA (concurrently exploring an understudied area of Internet use in adolescence), this study investigated the role of IPV preference as an IA risk factor during the period of late adolescence (16-18 years) and in relation to characteristics of adolescent classrooms.

For consistency with past Greek studies (i.e., Giotakos et al., 2017; Kalaitzaki \& Birtchnell, 2014; Stavropoulos, Alexandraki, \& Motti-Stefanidi, 2013; Stavropoulos, Gentile, \& Motti-Stefanidi, 2016; Stavropoulos, Kuss, Griffiths, Wilson, \& Motti-Stefanidi, 2017), this study adopts the IA construct and its associated definitions and measures

\footnotetext{
* Corresponding authors: Tyrone L. Burleigh; Federation University, Mount Helen, VIC, Australia; Phone: +61 41221 8117; E-mail: tyrone.1.burleigh@gmail.com; Vasileios Stavropoulos; Cairnmillar Institute, 391-393 Tooronga Road, Hawthorn East 3123, VIC, Australia; Phone: +61 039813 3400; Fax: +61 03 9882 9764; E-mail: vas@cairnmillar.edu.au
}

This is an open-access article distributed under the terms of the Creative Commons Attribution-NonCommercial 4.0 International License, which permits unrestricted use, distribution, and reproduction in any medium for non-commercial purposes, provided the original author and source are credited, a link to the CC License is provided, and changes - if any - are indicated. 
(Young \& Rogers, 1998). Here, IA refers to the use of the Internet in a manner that is continuous and compulsive and causes detrimental consequences to everyday life (Young, Pistner, O’Mara, \& Buchanan, 1999). This approach conceptualizes Internet use as a global construct without distinguishing the types of online activities and applications that the users might be involved with (Griffiths, Kuss, Billieux, \& Pontes, 2016; Király, Nagygyörgy, Koronczai, Griffiths, \& Demetrovics, 2015; Starcevic \& Billieux, 2017). For the purpose of this study, IA was investigated in relation to IPV preference using an integrative conceptual framework (Stavropoulos, Gentile, et al., 2016).

This integrative framework considers the manifestations of IA (e.g., preoccupation with the Internet and lying to others about the amount of Internet use) along a continuum ranging from minimum to maximum severity and focuses on the interplay between "push" and "pull" factors over the psychosocial development of the Internet user (Stavropoulos, Gentile, et al., 2016). Push factors contribute to IA and include developmental changes (maturation), gender, characteristics of the individual, and factors within the individual's close personal context (i.e., school classroom, where adolescents spent a lot of time, interacting and observing each other). Pull factors (increasing IA risk) refer to characteristics related to communicative features of the medium (e.g., flow and presence). Based on this model, this study longitudinally investigated the (likely) individual IA risk contribution of IPV preference of adolescents aged 16-18 years, in relation to the potential moderating effects of the classroom context.

\section{Late adolescence}

Late adolescence (16-18 years) is a critical period for romantic/sexual development, as well as Internet use/IA (Anderson et al., 2016; Dhariwal \& Connolly, 2013). It has been postulated that adolescents tend to develop sexual attractions and affiliations in early adolescence (11-13 years) and that leads to the exploration of romantic sexual relationships in middle adolescence (14-16 years). Usually, between the ages of 16 and 18 years, adolescents tend to consolidate (e.g., develop a specific approach/style) their sexual behaviors (Connolly \& McIsaac, 2011). Simultaneously, Internet use increases among young people throughout adolescence and can be another medium for sexual exploration (Dhariwal \& Connolly, 2013). Consequently, this study investigates the IPV-IA association between the ages of 16 and 18 years.

\section{IPV and Internet}

IPV has been consistently identified as a risk factor for IA in adolescence (Anderson et al., 2016). Frequent and prolonged Internet use is positively associated with IPV in adolescent populations (Mesch, 2009; Ševčíková, Šerek, Macháčková, \& Šmahel, 2013). Furthermore, a small proportion of Internet pornography users (up to 8.8\%) report IA (Tsitsika et al., 2009). This is consistent with longitudinal findings reporting that IPV increases the risk of compulsive Internet use (Doornwaard, van Den Eijnden, Baams, Vanwesenbeeck, \& Ter Bogt, 2016; Meerkerk, Eijnden, \& Garretsen, 2006). Sexual gratification combined with lower levels of psychological well-being (e.g., low mood) and elevated sexual interest during adolescence have been suggested as contributing to this association (Doornwaard et al., 2016; Meerkerk et al., 2006). In accordance with these findings, Dhuffar and Griffiths (2015) asserted that IPV fueled by high sexual motivation can potentially become excessive, thus resulting in IA. Following this line of thought, various authors (e.g., Doornwaard et al., 2016; Griffiths, 2000, 2012) concluded that Internet convenience facilitates the ease in which pornography can be accessed, inevitably placing more vulnerable adolescents at higher risk of developing related addictive behaviors. In particular, the highly accessible, affordable, and anonymous features of IPV (aka the "triple A engine;" Cooper, 1998) have been claimed as facilitating and magnifying IA risk (Anderson et al., 2016; Griffiths, 2001). Although several studies have demonstrated a consistent relationship between adolescent IPV and IA, there is a dearth of longitudinal data on the variations in IPV and IA in relation to the social context of the school classroom.

\section{Classroom moderating effects}

Previous research has demonstrated the important role of the classroom context (as a proximal context) on adolescent development in general and the development of IA in particular (Kuperminc, Leadbeater, \& Blatt, 2001; Leadbeater, Hoglund, \& Woods, 2003; Stavropoulos, Gentile, et al., 2016; Stavropoulos, Kuss, et al., 2017). This trend has been influenced by the extension of developmental psychology models with an ecological focus to school settings (Bronfenbrenner \& Morris, 1998; Hamre \& Pianta, 2005; Zhou \& Fang, 2015). This is in consensus with the importance of the social context of the classroom for the development of normative social behaviors through interactions and observations (Lerner, 1998; Sameroff, 1995, 2000). Along this line, findings have suggested that the average levels of several classroom characteristics, such as social competence, emotional problems, and behavioral problems, have moderating effects on adolescents' psychosocial well-being (Leadbeater et al., 2003). Considering IA in particular, studies have supported the moderating role of classroom on the IA risk effects of both symptoms of anxiety and obsessiveness-compulsiveness, as well as the preference of playing Massively Multiplayer Online Role-Playing Games (Stavropoulos, Gomez, et al., 2017; Stavropoulos, Kuss, et al., 2017; Stavropoulos, Kuss, Griffiths, \& Motti-Stefanidi, 2016). More specifically, it has been argued that the average levels of specific personality traits within classroom can either buffer or exacerbate IA vulnerability. Indicatively, extraversion (e.g., a personality trait involving tendencies to display social behaviors, experience and express positivity, and project high energy and levels of activity) has been found to reduce the IA risk of more anxious adolescents (Stavropoulos, Gomez, et al., 2017). Given that extraversion as a group characteristic (e.g., the average level of extraversion of the members of a group) has been associated with a higher sense of group cohesion and improved communication between individuals, it has been hypothesized that a classroom with more extraverted students can accommodate social fulfillment, consequently 
reducing IA tendencies (Barrick, Stewart, Neubert, \& Mount, 1998; Stavropoulos, Gomez, et al., 2017). Given this, it could be assumed that the IA risk effect of an adolescent who has a preference for IPV (in preference to other Internet applications) might be increased within a more introverted classroom.

On the other hand, one could also expect that the IA risk of adolescents preferring IPV could be reduced when they are situated in classrooms of a higher average level of openness to experience (OTE). OTE has been suggested as promoting socialization because it involves mixed tendencies of creativity, flexibility, curiosity, and a potentially adventurous attitude toward life (McCrae \& Sutin, 2009). Therefore, individuals who experience higher levels of OTE have been shown to seek feedback and have positive perceptions of relationships (Wanberg \& KammeyerMueller, 2000). These socially proactive characteristics, along with novelty-seeking and tolerance to differences could have the capacity to advance positive peer relations (Wanberg \& Kammeyer-Mueller, 2000), reducing the need of escape online to achieve satisfaction through IPV (Doornwaard et al., 2016; Meerkerk et al., 2006).

Despite the progress in the literature considering the moderating effects of the classroom context on individual IA risk factors during adolescence, no previous studies have concurrently examined how an individual's level of IA risk could unfold differently (e.g., increase or decrease) across classrooms concurrently differing on introversion and OTE. This study adds to the field by investigating the interactions over time of more introverted and higher on OTE classrooms with the adolescent IPV preference in relation to individuals' IA risk. To address this aim, the nesting of the present data was utilized (i.e., individuals within classrooms) and the recommended methodology of aggregating individual personality scores to produce average group-level traits was applied (Barrick et al., 1998; Halfhill, Sundstrom, Lahner, Calderone, \& Nielsen, 2005; Homan et al., 2008; McCrae \& Terracciano, 2005; Neuman, Wagner, \& Christiansen, 1999; Schilpzand, Herold, \& Shalley, 2010).

\section{The present study}

This study investigated a normative sample of Greek adolescents aged 16 years and again at the age of 18 years. The influence of IPV preference was examined as a risk factor related to the individual in the light of age-related changes between 16 and 18 years of age and in relation to the contextual effects of classroom introversion and OTE. Based on the literature to date, the following three hypotheses were formulated:

Hypothesis $1\left(H_{1}\right)$ : The preference of IPV will increase the risk of adolescents developing IA (Dhuffar \& Griffiths, 2015; Doornwaard et al., 2016; Meerkerk et al., 2006). Sexual arousal - co-presents with lower mood during adolescence - might contribute to this association (Doornwaard et al., 2016; Meerkerk et al., 2006). Given the demonstrated stability of IA among adolescents (Shek \& Yu, 2012), the above relationship was also expected to remain stable over time.

Hypothesis $2\left(\mathrm{H}_{2}\right)$ : The IA risk effect of IPV preference will be exacerbated over time within more introverted classrooms (Stavropoulos, Gomez, et al., 2017). This is based on evidence suggesting that classroom characteristics have moderating effects on adolescents' psychosocial well-being and IA behaviors in particular (Leadbeater et al., 2003; Stavropoulos, Gomez, et al., 2017). More specifically, provided that group extraversion results in a higher sense of group cohesion and improved communication (Barrick et al., 1998; Stavropoulos, Gomez, et al., 2017), it is arguable that the IA risk of adolescents with a preference for IPV might be increased within more introverted classrooms.

Hypothesis $3\left(\mathrm{H}_{3}\right)$ : The IA risk effect of IPV preference will be buffered over time within classrooms higher on OTE (Stavropoulos, Gentile, et al., 2016). Based on the previous literature, which highlights that socially proactive characteristics, along with novelty-seeking and tolerance to differences (associated to OTE), advance positive peer relations (Wanberg \& Kammeyer-Mueller, 2000), it is hypothesized that individuals may reduce the need of escaping online to achieve satisfaction through IPV (Doornwaard et al., 2016; Meerkerk et al., 2006).

\section{METHODS}

\section{Participants}

Participants were recruited from the Athens metropolitan area and a chosen regional area (Korinthia) following randomized stratified selection, based on the latest data released by the Ministry of Education. The high schools that were included were randomly selected. The sample comprised 648 students in 34 classrooms in Greek public, academic, and vocational track high schools. The distribution of the sample did not significantly differ from that of the original population regarding the area of residence and the type of school attended $\left(\chi^{2}=3.83, p=.75\right)$.

Participants were assessed twice within two school years [individual-level Wave 1: mean age $=15.75$ years, $S D=0.57 \quad$ years, $\quad$ boys $=301 \quad(46.4 \%), \quad$ girls $=347$ $(53.6 \%)$, academic track high schools $=540(83.2 \%)$, vocational track high schools $=108(16.7 \%)$, Athens metro area $=600(92.6 \%)$, Korinthia $=48(7.4 \%)$; individual-level Wave 2: mean age $=17.75$ years, $S D=0.54$ years, boys $=181(49.9 \%)$, girls $=182(50.1 \%)$, academic track high schools $=292(80.3 \%), \quad$ vocational track high schools $=71(19.7 \%)$, Athens metro area $=326(89.9 \%)$, Korinthia $=37$ (10.1\%); group-classroom-level Waves 1 and 2: one classroom (2.9\%), vocational track Korinthia; three classrooms $(8.8 \%)$, academic track Korinthia; five classrooms (14.7\%), vocational track Athens metro area; 25 classrooms (73.5\%), Athens metro area].

The analysis of the socioeconomic status of participants showed that $78.7 \%$ of parents were married, the unemployment rate was $8.3 \%$ among mothers and $8.6 \%$ among fathers, whereas $89 \%$ of mothers and $87 \%$ of fathers had completed secondary education. At Time 1, Internet usage was a $100 \%$ with $21 \%$ predominantly accessing blogs and social networking sites, $16.4 \%$ instant messengers, $14.6 \%$ information-seeking engines, $13.6 \%$ chat rooms, $13.4 \%$ online games, $13.4 \%$ YouTube and other video services, $2.4 \%$ pornographic sites (adolescents of interest in this 
study), and 5\% other applications. Parental consent was $98 \%$ and the students' response rate was over 95\%. The estimated maximum sampling error with a sample size of 648 is $3.85 \%$ at the $95 \%$ confidence level $(Z=1.96)$.

Retention between Waves 1 and 2 was $56 \%$ due to the changes of school and research dropouts of participants. Therefore, systematic evaluation of the attrition effects on the examined variables was conducted and did not indicate any significant associations. Furthermore, attrition was used as an independent variable (dummy coded $1=$ attrition and $0=$ not attrition) at Level 2 of hierarchical linear modeling (HLM) analyses to assess whether it affected IA scores and its interactions with IPV preference and classroom introversion and OTE.

\section{Instruments}

Internet Addiction Test (IAT). Despite a wide range of psychometrically robust instruments to assess IA (King, Haagsma, Delfabbro, Gradisar, \& Griffiths, 2013; Király et al., 2015), this study employed the IAT (Young, 1998) to assess IA risk, thus allowing comparability with previous Greek studies (e.g., Siomos, Dafouli, Braimiotis, Mouzas, \& Angelopoulos, 2008; Stavropoulos et al., 2013). The IAT contains 20 questions examining the occurrence of negative consequences of addictive Internet use (e.g., "How often do you find that you stay online longer than intended?" and "How often do you choose to spend more time online over going out with others?"). Each item is on a 5-point Likert scale (ranging from 0 "it does not concern me" to $5=$ "always"). Scores are added together with a total ranging from 0 to 100 , where 0 indicated minimum and 100 indicated maximum IA symptoms. The internal rate of reliability for the present data had a Cronbach's $\alpha$ of .93.

Internet pornography viewing (IPV). Participants reported as their most preferred (most used) Internet application (e.g., they had visited most frequently in the last 6 months) choosing one of the following options: (a) social networking sites and blogs, (b) e-mails and instant messengers, (c) downloading videos or music, (d) information seeking, (e) online gaming, (f) Internet pornography, and (g) other. Examples were provided following each option (e.g., for IPV: thesextube. net, xtube.com, sextube.si, etc.). For consistency with the literature, IPV was defined to the participants as viewing online or downloading pictures and videos with clearly exposed genitals and/or pictures or videos in which people were having sex (with the intention of eliciting a sexual reaction; Peter \& Valkenburg, 2009). Therefore, this definition did not include sexting, engaging in cybersex, or blind dating with another individual through Internet. Furthermore, it was clarified to the participants that IPV included accessing relevant material only as a spectator or audience. The answers were dummy recoded with 1 referring to participants who indicated IPV as their most frequently used (preferred) online application and 0 for the remaining participants.

Five Factor Questionnaire for children and adolescents: Introversion and OTE subscales. To assess introversion and OTE at the classroom level, the relevant subscales of the Five Factor Questionnaire were used (Asendorpf \& van Aken, 2003). The questionnaire is composed of five subscales: extraversion/introversion, emotional stability, conscientiousness, agreeableness, and OTE. Each subscale included eight bipolar adjectives (i.e., "I have no interests-I have many interests") on a 5-point scale (i.e., $1=$ very, $2=$ somewhat, $3=$ neither/nor, $4=$ somewhat, and $5=$ very) situated in between each adjective. The mean of the items was compiled, and each subscale was calculated, resulting in a range from 1 to 5 , indicating the minimum and the maximum presence of each trait. Each with the following Cronbach's $\alpha$ : extraversion/introversion $=.74$, emotional stability $=.55$, agreeableness $=.63$, conscientiousness $=.67$, and OTE $=.73$. To assess classroom introversion and OTE, individual scores within the same classroom were aggregated to produce the classroom mean average score, in line with the previous studies (Barrick et al., 1998; Stavropoulos, Gentile, et al., 2016).

\section{Procedure}

The process of data collection was the same across the two time points. A specially trained research team of 13 undergraduates, postgraduates, and PhD students of the Department of Psychology of the University of Athens collected the data in the participants' classrooms during the first two or the last two school hours (45 min each) of a school day, in accordance with the permission provided by the Ministry of Education.

\section{Statistical analyses}

Multilevel modeling was used to statistically analyze a data structure where measurements at two time points (Level 1) were nested within individuals (Level 2), who were nested within classrooms (Level 3) [This approach was chosen to enable this study to disentangle and examine age-related changes on IA symptoms at Level 1, considering the effects of an individual push factor (i.e., IPV preference) at Level 2, and in relation to its interaction with two contextual factors (i.e., classroom introversion and OTE) at Level 3. Conducting covariance-based structural equation modeling was not selected as (a) it requires at least three or four indicators (this study includes two time points, which enable the examination of linear and not quadratic or cubic growth patterns; Chatfield, 2016) for every latent variable (growth; Baumgartner \& Homburg, 1996) and (b) it assumes multinormal distribution of the observed variables to ensure meaningful results, which is rarely the case in empirical research (Micceri, 1989). Similarly, latent growth modeling was not chosen as it assumes that Level-1 predictors with random effects have the same distribution across all participants in each subpopulation, while HLM allows different distributions (Raudenbush \& Bryk, 2002). Finally, HLM was preferred over partial least square analysis and repeated measures of ANOVA, as it estimates the effects of variables on the outcome variable at one level (i.e., individual), while simultaneously considering the effect of variables on the outcome variable at another level (i.e., classroom; Raudenbush \& Bryk, 2002). Subsequently, the HLM 6.0.8 software was used (Raudenbush, 2004). Model testing proceeded in successive phases (i.e., unconstrained model, random intercepts model, and means-as-outcome and slopes-as-outcome models for IPV and classroom 
extraversion and OTE (Level-2 and Level-3 predictors), and the full model). For reasons of succinctness, and given that the results did not significantly differ, only the full model will be reported here.]. IA symptoms (Level 1 outcome variable) were predicted for each individual at Level 1 by time in this study. Time was centered at Time 1 such that the individual intercepts referred to the initial level of IA (Wave $1=0$ and Wave $2=1$ ). The individual initial level and the individual linear change over the two assessments (slope) were predicted at Level 2 by IPV preference (IPV not the most preferred $=0$ and IPV the most preferred $=1$ ). Finally, the contextual effects due to the levels of classroom introversion and OTE were estimated through random effects equations at Level 3 regarding both the main effect of IPV preference as well as its cross-level interaction with time [To control misspecification (i.e., lack of linearity) and the distributional assumptions at each level (i.e., lack of normality and heteroscedasticity), HLM results - accounting for robust standard errors (which are insensitive to possible violations of these assumptions) - were calculated. It should be noted that the sample size requirements to assess crosslevel interactions (i.e., fixed and random effects) were addressed. The "rule of thumb" for defining sample sizes were avoided, due to the existence of complex and interactive relationships between factors that affect power (Mathieu, Aguinis, Culpepper, \& Chen, 2012). Considering fixed effects and cross-level interactions, studies using random-intercept and random-coefficients models with a single explanatory variable at each of the levels (similar to this study) have shown that 10-12 clusters (34 clusters in this study), paired with cluster sizes ranging from 5 to 20 (15-20 participants per classroom in this study), are sufficient to produce accurate point estimates of fixed effects and cross-level interactions (Maas \& Hox, 2004, 2005). Considering standard errors of fixed effects, this study abided with the minimum requirement of 30 clusters for empirical coverage of the $95 \%$ confidence interval (Maas \& Hox, 2004, 2005).].

\section{Ethics}

All procedures performed in the study involving human participants were in accordance with the ethical standards of the institutional and/or national research committee and with the 1964 Helsinki declaration and its later amendments or comparable ethical standards. The Institutional Review Board of the National and Kapodistrian University of Athens approved the study. All subjects were informed about the study and all provided informed consent. Parental consent was sought for those younger than 18 years of age. This article does not contain any studies with animals performed by any of the authors.

\section{RESULTS}

\section{Missing values}

Potential confounding effects due to attrition were confirmed as insignificant (Table 1). Missing values did not present a problem at Level 1 (measurements within
Table 1. Attrition, Internet pornography preference, classroom openness to experience, and introversion on Internet addiction

\begin{tabular}{|c|c|c|c|c|c|}
\hline & \multicolumn{5}{|c|}{$\begin{array}{l}\text { Fixed effects with robust } \\
\text { standard errors }\end{array}$} \\
\hline & $b_{i}$ & $S E$ & $T$ & $d f$ & $p_{i}$ \\
\hline Attrition & 3.91 & 2.05 & 1.91 & 31 & .07 \\
\hline $\begin{array}{l}\text { Internet pornography } \times \\
\text { Attrition }\end{array}$ & 19.11 & 23.87 & 0.80 & 33 & .43 \\
\hline $\begin{array}{l}\text { Classroom level of } \\
\text { openness to experience } \times \\
\text { Attrition }\end{array}$ & 5.50 & 8.86 & 0.62 & 31 & .54 \\
\hline $\begin{array}{l}\text { Classroom level of } \\
\text { introversion } \times \text { Attrition }\end{array}$ & 13.86 & 17.77 & 0.78 & 31 & .44 \\
\hline
\end{tabular}

individuals) and did not occur at Level 3 (classroom). However, they had to be addressed at Level 2. To avoid listwise deletion, multiple imputation was applied (five maximum likelihood imputations using SPSS) using all available Level 2 (individual) variables (Table 1). Therefore, all equations were calculated five times, and the results were averaged in accordance with the recommendations of MottiStefanidi, Asendorpf, and Masten (2012).

\section{Intraclass correlation}

To ensure that all three levels contributed to variation in IA scores, the level components were calculated from the unconditional model $\left(\chi^{2}\right.$ Level $2=1,272.85, d f=596$, $p=.001 ; \chi^{2}$ Level $\left.3=46.93, d f=33, p=.001\right)$. Therefore, HLM equations to address the relevant hypotheses were calculated (Table 2).

\section{Hypotheses testing}

To test $H_{l}$, time (centered at Wave 1) and IPV (centered at those who preferred Internet pornography) were inserted at Levels 1 and 2, respectively, such that the individual intercepts referred to the initial level of IA of participants who did not report IPV as their first preference. Findings demonstrated that IA risk had significantly increased $(b=10.56$, $p<.001)$ for those who preferred IPV and this did not differ between 16 and 18 years $(b=-3.05, p<.05)$ (i.e., it did not interact with time and therefore the effect remained significant, but its change over time was insignificant).

To test $H_{2}$, time and IPV were inserted at Levels 1 and 2, respectively, similarly to $H_{l}$. Furthermore, the average level of OTE in classroom was inserted (grand centered) at Level 3. Findings demonstrated that the IA risk of those who reported IPV as their first preference significantly dropped between 16 and 18 years $(b=-23.51, p<.05)$, when they were situated in classrooms of higher average level of OTE (Figure 1).

To test $H_{3}$, time and IPV were inserted at Levels 1 and 2, respectively, similarly to $H_{1}$ and $H_{2}$. Furthermore, the average level of introversion in classroom was inserted (grand centered) at Level 3. Findings demonstrated that those who preferred IPV were at increased IA risk over time, when situated in more introverted classrooms $(b=-41.38$, $p<.01$; Table 3, Figure 2). 
Table 2. Three level equations calculated for each hypothesis

\begin{tabular}{|c|c|c|c|}
\hline & $H_{2 b}$ & $\mathrm{H}_{2 c}$ & $H_{3}$ \\
\hline Level 1 & $\mathrm{IA}=\pi_{0}+\pi_{1} \times(\mathrm{WAVE})+\varepsilon$ & $\mathrm{IA}=\pi_{0}+\pi_{1} \times(\mathrm{WAVE})+\varepsilon$ & $\mathrm{IA}=\pi_{0}+\pi_{1} \times(\mathrm{WAVE})+\varepsilon$ \\
\hline \multirow[t]{3}{*}{ Level 2} & $\pi_{0}=\beta_{00}+\beta_{01} \times($ Por $)+\rho_{0}$ & $\pi_{0}=\beta_{00}+\beta_{01} \times($ Por $)+\rho_{0}$ & $\pi_{0}=\beta_{00}+\beta_{01} \times($ Por $)+\rho_{0}$ \\
\hline & $\pi_{1}=\beta_{10}+\beta_{11} \times($ Por $)+\rho_{1}$ & $\pi_{1}=\beta_{10}+\beta_{11} \times($ Por $)+\rho_{1}$ & $\pi_{1}=\beta_{10}+\beta_{11} \times($ Por $)+\rho_{1}$ \\
\hline & $\pi_{2}=\beta_{20}+\beta_{21} \times($ Por $)+\rho_{2}$ & $\pi_{2}=\beta_{20}+\beta_{21} \times($ Por $)+\rho_{2}$ & $\pi_{2}=\beta_{20}+\beta_{21} \times($ Por $)+\rho_{2}$ \\
\hline \multirow[t]{6}{*}{ Level 3} & $\beta_{00}=\gamma_{000}+u_{00}$ & $\beta_{00}=\gamma_{000}+\gamma_{001}$ (Class OTE $)+u_{00}$ & $\beta_{00}=\gamma_{000}+\gamma_{001}$ (Class Intr. $)+u_{00}$ \\
\hline & $\beta_{01}=\gamma_{010}+u_{01}$ & $\beta_{01}=\gamma_{010}+\gamma_{011}$ (Class OTE $)+u_{01}$ & $\beta_{01}=\gamma_{010}+\gamma_{011}$ (Class Intr. $)+u_{01}$ \\
\hline & $\beta_{10}=\gamma_{100}+u_{10}$ & $\beta_{10}=\gamma_{100}+\gamma_{101}$ (Class OTE $)+u_{10}$ & $\beta_{10}=\gamma_{100}+\gamma_{101}$ (Class Intr. $)+u_{10}$ \\
\hline & $\beta_{11}=\gamma_{110}+u_{11}$ & $\beta_{11}=\gamma_{110}+\gamma_{111}$ (Class OTE $)+u_{11}$ & $\beta_{11}=\gamma_{110}+\gamma_{111}$ (Class Intr. $)+u_{11}$ \\
\hline & $\beta_{20}=\gamma_{200}+u_{20}$ & $\beta_{20}=\gamma_{200}+\gamma_{201}$ (Class OTE $)+u_{20}$ & $\beta_{20}=\gamma_{200}+\gamma_{201}$ (Class Intr.) $+u_{20}$ \\
\hline & $\beta_{21}=\gamma_{210}+u_{21}$ & $\beta_{21}=\gamma_{210}+\gamma_{211}$ (Class OTE $)+u_{21}$ & $\beta_{21}=\gamma_{210}+\gamma_{211}$ (Class Intr. $)+u_{21}$ \\
\hline
\end{tabular}

Note. Por: pornograpghy; Class OTE: classroom openness to experience; Class Intr.: classroom introversion.

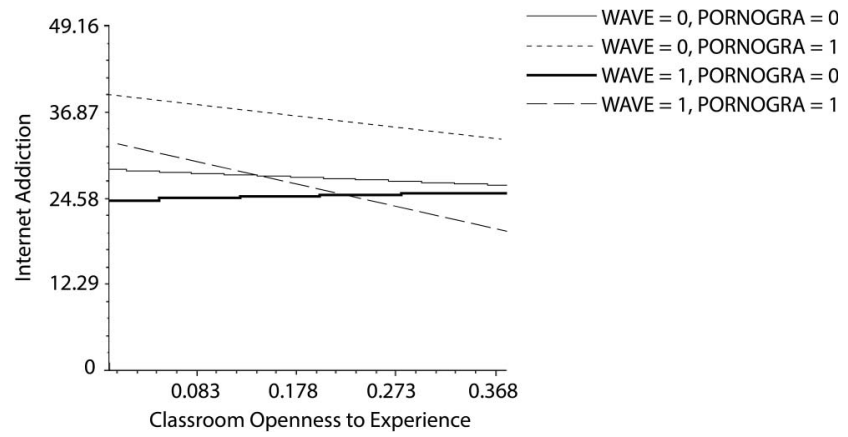

Figure 1. The moderating effect of an open to experience classroom on Internet addiction in frequent Internet pornography users

\section{DISCUSSION}

This study longitudinally examined the effect of IPV on IA and the potential moderating effects of classroom introversion and OTE in a normative sample of Greek adolescents aged 16 years and again at 18 years (Stavropoulos, Gentile, et al., 2016). More specifically, age-related variations on the

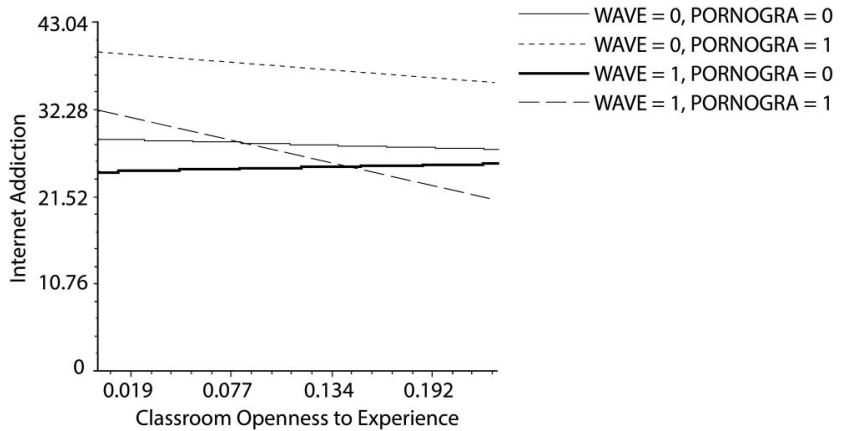

Figure 2. The negatively moderating effect on an introverted classroom on Internet addiction in frequent Internet pornography users

effect of IPV preference, as an individual-level "push" factor (i.e., factors that increase vulnerability to IA), and classroom introversion and OTE, as its social context moderators, were assessed. Successive three-level hierarchical linear models were applied. The results demonstrated that IPV preference was associated with higher IA scores. Although this relationship did not significantly vary over time, it differed across contexts. More specifically, classroom

Table 3. Internet addiction scores, Internet pornography (Int. Porn) preference, classroom openness to experience, and classroom introversion (Class Intr.)

\begin{tabular}{|c|c|c|c|c|c|c|c|c|c|c|c|}
\hline \multirow[b]{3}{*}{ Hypotheses } & & \multicolumn{10}{|c|}{ IAT score } \\
\hline & & \multicolumn{5}{|c|}{ Fixed effects without robust standard errors } & \multicolumn{5}{|c|}{ Fixed effects with robust standard errors } \\
\hline & & $b_{i}$ & $S E$ & $T$ & $d f$ & $p_{1}$ & $b_{i}$ & $S E$ & $T$ & $d f$ & $p_{1}$ \\
\hline \multicolumn{12}{|c|}{ Initial level (initial level as outcome models) } \\
\hline \multirow[t]{2}{*}{$H_{1}$} & Intercept & 28.76 & 1.02 & 28.24 & 33 & .000 & 28.76 & 0.98 & 29.37 & 33 & .000 \\
\hline & Int. Porn & 10.56 & 3.87 & 2.73 & 33 & .011 & 10.56 & 2.77 & 3.81 & 33 & .001 \\
\hline $\mathrm{H}_{2}$ & Int. Porn $\times$ Class OTE & -13.20 & 12.96 & -1.02 & 32 & .317 & -13.20 & 8.50 & 1.55 & 32 & .130 \\
\hline $\mathrm{H}_{3}$ & Int. Porn $\times$ Class Intr. & -12.72 & 22.39 & -0.57 & 32 & .574 & -12.72 & 15.77 & -0.81 & 32 & .426 \\
\hline \multicolumn{12}{|c|}{ Slope (initial level and slope as outcome models) according to age } \\
\hline \multirow[t]{2}{*}{$H_{1}$} & Intercept (time) & -4.09 & 1.34 & -3.05 & 33 & .005 & -4.09 & 1.34 & -3.06 & 33 & .005 \\
\hline & Int. Porn & -3.05 & 4.67 & -0.65 & 33 & .518 & -3.05 & 3.87 & -0.79 & 33 & .437 \\
\hline $\mathrm{H}_{2}$ & Int. Porn $\times$ Class OTE & -23.51 & 15.68 & -1.50 & 32 & .144 & -23.51 & 9.84 & -2.39 & 32 & .023 \\
\hline $\mathrm{H}_{3}$ & Int. Porn $\times$ Class Intr. & -41.38 & 24.96 & -1.66 & 32 & .107 & -41.38 & 14.46 & -2.86 & 32 & .008 \\
\hline
\end{tabular}

Note: Reported are the significances $p_{i}$ for increased fit by adding predictors of initial level and age-related changes of IA scores and the unstandardized initial regression coefficients $b_{i}$ with the Levels 1-3 predictors. Wave is centered at 16 and cyberpornography on those who did not prefer it. IAT: Internet Addiction Test; OTE: openness to experience. 
introversion exacerbated the IA risk effect of IPV preference, and higher classroom OTE buffered it.

\section{$I P V$ and $I A$}

IPV preference was found to significantly increase IA risk at the age of 16 years and did not significantly vary over time (between 16 and 18 years). This is consistent with a past research, which has demonstrated higher IA risk for individuals who participate in IPV (Dhuffar \& Griffiths, 2015; Doornwaard et al., 2016; Meerkerk et al., 2006; Tsitsika et al., 2009). This finding was significant within the developmental context of late adolescence (16-18 years), during which individuals tend to consolidate their sexual behaviors, concurrently increasing their Internet engagement (Anderson et al., 2016; Collins, 2003). It is therefore reasonable to assume that a higher sense of satisfaction associated with IPV (e.g., positive immediate gratification effect through sexual stimulation) may coexist with lower mood and higher sexual urges (common among adolescents), and could explain the IPV preference relating to higher IA risk (Doornwaard et al., 2016; Meerkerk et al., 2006). This aligns with theoretical hypotheses that IPV, combined with high sexual drives, is likely to become excessive and lead to IA (Dhuffar \& Griffiths, 2015). The latter could be reinforced by the Internet interface [e.g., flexibility, convenience, anonymity, accessibility, affordability, and disinhibition (Cooper, 1998; Doornwaard et al., 2016; Griffiths, 2010)] placing more vulnerable adolescents at higher risk of IA (Anderson et al., 2016).

The relationship between IPV and IA did not present with age-related variations between 16 and 18 years. This is in consensus with studies showing that IA intensity during adolescence remains stable over time change (Shek \& Yu, 2012). This has been attributed to the establishment of specific pathological behavioral patterns (e.g., mood modification, rewards, and withdrawal symptoms) which generate resistance to change (Shek \& Yu, 2012). Therefore, it is likely that when IPV preference and IA co-occur at the age of 16 years, they progressively become established behaviors (partially through reinforcing each other) and are less likely to change over time. Thus, indicating the need for more vulnerable adolescents, presenting with an IPV preference, to be targeted for IA prevention before the age of 16 years.

\section{Classroom moderating effects}

Considering the potential classroom moderating effects on the IPV-IA association, findings indicated that while the IPV preference related to IA risk increased in classrooms higher in introversion, it reduced over time in classrooms higher in OTE. Findings in this study appear in line with broader literature illustrating the developmental significance of the classroom context (as a proximal context) for adolescents in general, as well as IA in particular (Kuperminc et al., 2001; Leadbeater et al., 2003; Stavropoulos, Gentile, et al., 2016; Stavropoulos, Gomez, et al., 2017; Stavropoulos, Kuss, et al. 2017). Along that line, one could assume that introversion as a classroom characteristic (i.e., the average level of introversion between students of the same classroom) could compromise communication and sexual exploration between adolescents (e.g., developmentally expected activities, such as flirting or sex talks; Collins, 2003), thus likely directing them to the escape in their IPV context, inducing IA (Barrick et al., 1998; Stavropoulos, Gomez, et al., 2017). This could be particularly important among adolescents, who present with an IPV preference, because their potential for sexual engagement, development, experimentation, and interactions might decrease in more introverted classrooms, reinforcing their IPV drives to address their unmet needs (potentially a social contagion effect of classroom introversion; Doornwaard et al., 2016; Meerkerk et al., 2006).

Similarly, the IA risk of adolescents preferring IPV was reduced in classrooms with a higher level of OTE. Higher levels of OTE have been suggested to advance socialization and levels of acceptance regarding several behaviors (e.g., less frequent and/or socially accepted), such as a preference for IPV (McCrae \& Sutin, 2009). Therefore, classrooms that are higher in OTE may display socially proactive characteristics. This may result in novelty-seeking and tolerance toward differences that could facilitate several forms of sexual exploration, including IPV (Wanberg \& Kammeyer-Mueller, 2000), decreasing alienation of adolescents who prefer IPV (Doornwaard et al., 2016; Meerkerk et al., 2006). Therefore, the IPV preference and related IA risk could be positively moderated by belonging in a classroom that has a high level of OTE. Overall, the present findings corroborate the IA literature developments considering the moderating effects of the classroom context on individual IA risk factors during adolescence. Furthermore, they expand available knowledge by highlighting how IPV and the related IA risk could unfold differently (i.e., increase or decrease) across classrooms varying on introversion and OTE. Therefore, IA school-associated prevention and intervention initiatives (e.g., psychoeducation and cyber-safety sessions, introduction of self-help groups) should carefully target increasing extraversion- and OTErelated classroom features to moderate adolescent IA risk presenting with an IPV preference.

\section{Limitations}

Similar to other studies, IPV was assessed with a binary question and not a standardized questionnaire. Furthermore, the current study item on IPV enquired about "preference" (e.g., IPV as the most used Internet application). This approach could be skewed toward users who view more pornography (Bányai et al., 2017). Additionally, there is the probability that adolescent participants might not have disclosed their IPV preference due to social desirability bias. Moreover, the population of participants in this study comprised Greek adolescents between the age of 16 and 18 years. Therefore, cultural factors and age-related characteristics need to be considered.

Despite these limitations, this study has a number of significant strengths. These include the (a) longitudinal design; (b) target population's representativeness; (c) three-level hierarchical model which applied enabled the disentangling of individual IPV preference effects on IA, controlling for other individual and classroom level random effects; and (d) use of a non-US sample, thus expanding the corpus of nations in which the IPV preference and IA association has been examined. 


\section{CONCLUSION AND RECOMMENDATIONS FOR FUTURE RESEARCH}

This study demonstrated that the contribution of Internet pornography preference (as an IA risk factor) might be increased in more extroverted classrooms and decreased in OTE classrooms. As Meerkerk et al. (2006) indicated, the addictive nature of Internet pornography applications is related to the interactive features of the activity, the mechanisms of which are yet to be fully understood. Additional research on activity-related factors that contribute to the addictive nature of pornographic sites (e.g., online flow, presence, and identification) in addition to the frequency of pornographic use or problematic pornography use would increase the understanding of the phenomenon. Future research could also investigate the moderating role of classroom characteristics in younger adolescents where the problematic behaviors are not yet established, which may provide a unique insight into the etiology of IA.

Funding sources: Data collection in Greece for this study has been co-financed by the European Union (European Social Fund - ESF) and Greek national funds, under the Operational Program "Education and Lifelong Learning" of the National Strategic Reference Framework (NSRF) Research Funding Program: Heracleitus II. Data collection in Cyprus has been funded by the Cypriot Youth Organization.

Authors' contribution: KA contributed to writing - original draft, final draft, review and editing, the literature review, hypotheses formulation, structure, and sequence of theoretical arguments. VS contributed to writing - final draft, review and editing, data collection, and analyses. TLB contributed to writing - review and editing. DLK contributed to hypotheses formulation, structure, and sequence of theoretical arguments. MDG contributed to writing - review and editing.

Conflict of interest: The authors do not report any conflict of interest. They confirm that this paper has not been either previously published or submitted simultaneously for publication elsewhere.

Copyright: The authors assign copyright or license the publication rights in this article.

\section{REFERENCES}

Anderson, E. L., Steen, E., \& Stavropoulos, V. (2016). Internet use and problematic Internet use: A systematic review of longitudinal research trends in adolescence and emergent adulthood. International Journal of Adolescence and Youth, 22(3), 430-454. doi:10.1080/02673843.2016.1227716

Asendorpf, J. B., \& Van Aken, M. A. (2003). Validity of Big Five personality judgments in childhood: A 9 year longitudinal study. European Journal of Personality, 17(1), 1-17. doi:10.1371/journal.pone.0169839.1002/per.460

Bányai, F., Zsila, A., Király, O., Maraz, A., Elekes, Z., Griffiths, M. D., Andreassen, C. S., \& Demetrovics, Z. (2017). Problematic social media use: Results from a large-scale nationally representative adolescent sample. PLoS One, 12(1), e0169839. doi:10.1371/journal.pone.0169839

Barrick, M. R., Stewart, G. L., Neubert, M. J., \& Mount, M. K. (1998). Relating member ability and personality to work-team processes and team effectiveness. Journal of Applied Psychology, 83(3), 377. doi:10.1037/0021-9010.83.3.377

Baumgartner, H., \& Homburg, C. (1996). Applications of structural equation modeling in marketing and consumer research: A review. International journal of Research in Marketing, 13(2), 139-161. doi:10.1016/0167-8116(95)00038-0

Bleakley, A., Hennessy, M., \& Fishbein, M. (2011). A model of adolescents' seeking of sexual content in their media choices. Journal of Sex Research, 48, 309-315. doi:10.1080/ 00224499.2010.497985

Bronfenbrenner, U., \& Morris, P. A. (1998). The ecology of developmental processes. In W. Damon \& R. M. Lerner (Eds.), Handbook of child psychology: Vol. 1. Theoretical models of human development (5th ed.,, pp. 993-1028). New York, NY: John Wiley \& Sons.

Chatfield, C. (2016). The analysis of time series: An introduction. Boca Raton, FL: CRC Press.

Collins, W. A. (2003). More than myth: The developmental significance of romantic relationships during adolescence. Journal of Research on Adolescence, 13(1), 1-24. doi:10.1111/1532-7795.1301001

Connolly, J., \& McIsaac, C. (2011). Romantic relationships in adolescence. In M. K. Underwood \& L. H. Rosen (Eds.), Social development: Relationships in infancy, childhood, and adolescence (pp. 180-206). New York, NY: Guildford Press.

Cooper, A. (1998). Sexuality and the Internet: Surfing into the new millennium. CyberPsychology \& Behavior, 1(2), 187-193. doi:10.1089/cpb.1998.1.187

Dhariwal, A., \& Connolly, J. (2013). Romantic experiences of homeland and diaspora South Asian youth: Westernizing processes of media and friends. Journal of Research on Adolescence, 23(1), 45-56. doi:10.1111/j.1532-7795.2012. 00803.x

Dhuffar, M. K., \& Griffiths, M. D. (2015). A systematic review of online sex addiction and clinical treatments using CONSORT evaluation. Current Addiction Reports, 2(2), 163-174. doi:10. 1007/s40429-015-0055-x

Doornwaard, S. M., van Den Eijnden, R. J., Baams, L., Vanwesenbeeck, I., \& Ter Bogt, T. F. (2016). Lower psychological well-being and excessive sexual interest predict symptoms of compulsive use of sexually explicit Internet material among adolescent boys. Journal of Youth and Adolescence, 45(1), 73-84. doi:10.1007/s10964-015-0326-9

Giotakos, O., Tsouvelas, G., Spourdalaki, E., Janikian, M., Tsitsika, A., \& Vakirtzis, A. (2017). Internet gambling in relation to Internet addiction, substance use, online sexual engagement and suicidality in a Greek sample. International Gambling Studies, 17(1), 20-29. doi:10.1080/14459795.2016.1251605

Griffiths, M. D. (2000). Excessive Internet use: Implications for sexual behavior. CyberPsychology \& Behavior, 3, 537-552. doi:10.1089/109493100420151 
Griffiths, M. D. (2001). Sex on the Internet: Observations and implications for Internet sex addiction. Journal of Sex Research, 38(4), 333-342. doi:10.1080/00224490109552104

Griffiths, M. D. (2010). Internet abuse and Internet addiction in the workplace. Journal of Workplace Learning, 7, 463-472. doi:10.1108/13665621011071127

Griffiths, M. D. (2012). Internet sex addiction: A review of empirical research. Addiction Research and Theory, 20, 111-124. doi:10.3109/16066359.2011.588351

Griffiths, M. D., Kuss, D. J., Billieux, J., \& Pontes, H. M. (2016). The evolution of Internet addiction: A global perspective. Addictive Behaviors, 53, 193-195. doi:10.1016/j.addbeh.2015.11.001

Halfhill, T. R., Sundstrom, E., Lahner, J., Calderone, W., \& Nielsen, T. M. (2005). Group personality composition and group effectiveness: An integrative review of empirical research. Small Group Research, 36(1), 83-105. doi:10.1177/1046496404268538

Hamre, B. K., \& Pianta, R. C. (2005). Can instructional and emotional support in the first-grade classroom make a difference for children at risk of school failure? Child Development, 76(5), 949-967. doi:10.1111/j.1467-8624.2005.00889.x

Homan, A. C., Hollenbeck, J. R., Humphrey, S. E., Van Knippenberg, D., Ilgen, D. R., \& Van Kleef, G. A. (2008). Facing differences with an open mind: Openness to experience, salience of intragroup differences, and performance of diverse work groups. Academy of Management Journal, 51(6), 12041222. doi:10.5465/AMJ.2008.35732995

Kalaitzaki, A. E., \& Birtchnell, J. (2014). The impact of early parenting bonding on young adults' Internet addiction, through the mediation effects of negative relating to others and sadness. Addictive Behaviors, 39(3), 733-736. doi:10.1016/j.addbeh. 2013.12.002

King, D. L., Haagsma, M. C., Delfabbro, P. H., Gradisar, M., \& Griffiths, M. D. (2013). Toward a consensus definition of pathological video-gaming: A systematic review of psychometric assessment tools. Clinical Psychology Review, 33, 331-342. doi:10.1016/j.cpr.2013.01.002

Király, O., Nagygyörgy, K., Koronczai, B., Griffiths, M. D., \& Demetrovics, Z. (2015). Assessment of problematic Internet use and online video gaming. In E. Aboujaoude \& V. Starcevic (Eds.), Mental health in the digital age: Grave dangers, great promise (pp. 46-68). New York, NY: Oxford University Press.

Koletić, G. (2017). Longitudinal associations between the use of sexually explicit material and adolescents' attitudes and behaviors: A narrative review of studies. Journal of Adolescence, 57, 119-133. doi:10.1016/j.adolescence.2017.04.006

Kuperminc, G. P., Leadbeater, B. J., \& Blatt, S. J. (2001). School social climate and individual differences in vulnerability to psychopathology among middle school students. Journal of School Psychology, 39(2), 141-159. doi:10.1016/S0022-4405 (01)00059-0

Kuss, D. J., \& Lopez-Fernandez, O. (2016). Internet addiction and problematic Internet use: A systematic review of clinical research. World Journal of Psychiatry, 6(1), 143. doi:10.5498/ wjp.v6.i1.143

Leadbeater, B., Hoglund, W., \& Woods, T. (2003). Changing contexts? The effects of a primary prevention program on classroom levels of peer relational and physical victimization. Journal of Community Psychology, 31(4), 397-418. doi: $10.1002 /$ jcop. 10057
Lerner, R. M. (1998). Theories of human development: Contemporary perspectives. In W. Damon \& R. M. Lerner (Eds.), Handbook of child psychology: Theoretical models of human development (pp. 1-24). Hoboken, NJ: John Wiley \& Sons Inc.

Maas, C. J., \& Hox, J. J. (2004). The influence of violations of assumptions on multilevel parameter estimates and their standard errors. Computational Statistics \& Data Analysis, 46(3), 427-440. doi:10.1046/j.0039-0402.2003.00252.x

Maas, C. J., \& Hox, J. J. (2005). Sufficient sample sizes for multilevel modeling. Methodology: European Journal of Research Methods for the Behavioral and Social Sciences, 1(3), 86. doi:10.1027/1614-2241.1.3.86

Mattebo, M., Tydén, T., Häggström-Nordin, E., Nilsson, K. W., \& Larsson, M. (2013). Pornography consumption, sexual experiences, lifestyles, and self-rated health among male adolescents in Sweden. Journal of Developmental \& Behavioral Pediatrics, 34(7), 460-468. doi:10.1097/DBP.0b013e31829c44a2

Mathieu, J. E., Aguinis, H., Culpepper, S. A., \& Chen, G. (2012). Understanding and estimating the power to detect cross-level interaction effects in multilevel modeling. Journal of Applied Psychology, 97(5), 951-966. doi:10.1037/a0028380

McCrae, R. R., \& Sutin, A. (2009). Openness to experience. In M. R. Leary \& R. H. Hoyle (Eds.), Handbook of individual differences in social behavior (pp. 257-273). New York, NY: Guildford Press.

McCrae, R. R., \& Terracciano, A. (2005). Personality profiles of cultures: Aggregate personality traits. Journal of Personality and Social Psychology, 89(3), 407-425. doi:10.1037/00223514.89.3.407

Meerkerk, G. J., Eijnden, R. J. V. D., \& Garretsen, H. F. (2006). Predicting compulsive Internet use: It's all about sex! CyberPsychology \& Behavior, 9(1), 95-103. doi:10.1089/ cpb.2006.9.95

Micceri, T. (1989). The unicorn, the normal curve, and other improbable creatures. Psychological Bulletin, 105(1), 156. doi:10.1037/0033-2909.105.1.156

Mesch, G. S. (2009). Social bonds and Internet pornographic exposure among adolescents. Journal of Adolescence, 32(3), 601-618. doi:10.1016/j.adolescence.2008.06.004

Motti-Stefanidi, F., Asendorpf, J. B., \& Masten, A. S. (2012). The adaptation and well-being of adolescent immigrants in Greek schools: A multilevel, longitudinal study of risks and resources. Development and Psychopathology, 24(2), 451-473. doi:10.1017/S0954579412000090

Neuman, G. A., Wagner, S. H., \& Christiansen, N. D. (1999). The relationship between work-team personality composition and the job performance of teams. Group \& Organization Management, 24(1), 28-45. doi:10.1177/1059601199241003

Owens, E. W., Behun, R. J., Manning, J. C., \& Reid, R. C. (2012). The impact of Internet pornography on adolescents: A review of the research. Sexual Addiction \& Compulsivity, 19(1-2), 99-122. doi:10.1080/10720162.2012.660431

Peter, J., \& Valkenburg, P. M. (2006). Adolescents' exposure to sexually explicit material on the Internet. Communication Research, 33(2), 178-204. doi:10.1177/0093650205285369

Peter, J., \& Valkenburg, P. M. (2009). Adolescents' exposure to sexually explicit Internet material and sexual satisfaction: A longitudinal study. Human Communication Research, 35(2), 171-194. doi:10.1111/j.1468-2958.2009.01343.x 
Raudenbush, S. W. (2004). HLM 6: Hierarchical linear and nonlinear modeling. Lincolnwood, IL: Scientific Software International.

Raudenbush, S. W., \& Bryk, A. S. (2002). Hierarchical linear models: Applications and data analysis methods. (Vol. 1). Thousand Oaks, CA: Sage.

Reiner, I., Tibubos, A. N., Hardt, J., Müller, K., Wölfling, K., \& Beutel, M. E. (2017). Peer attachment, specific patterns of Internet use and problematic Internet use in male and female adolescents. European Child \& Adolescent Psychiatry, 26(10), 1257-1268. doi:10.1007/s00787-017-0984-0

Sameroff, A. J. (1995). General systems theories and developmental psychopathology. In D. Cicchetti \& D. J. Cohen (Eds.), Developmental psychopathology: Theory and methods (Vol. 1, pp. 659-695). Hoboken, NJ: John Wiley $\&$ Sons.

Sameroff, A. J. (2000). Developmental systems and psychopathology. Development and Psychopathology, 12(3), 297-312. doi:10.1017/S0954579400003035

Schilpzand, M. C., Herold, D. M., \& Shalley, C. E. (2010). Members' openness to experience and teams' creative performance. Small Group Research, 42, 55-76. doi:10.1177/ 1046496410377509

Ševčíková, A., Šerek, J., Macháčková, H., \& Šmahel, D. (2013). Extent matters: Exposure to sexual material among Czech adolescents. Journal of Early Adolescence, 33, 1048-1071. doi:10.1177/0272431613483004

Shek, D. T., \& Yu, L. (2012). Internet addiction phenomenon in early adolescents in Hong Kong. The Scientific World Journal, 2012, 1-9. doi:10.1100/2012/104304

Siomos, K. E., Dafouli, E. D., Braimiotis, D. A., Mouzas, O. D., \& Angelopoulos, N. V. (2008). Internet addiction among Greek adolescent students. CyberPsychology \& Behavior, 11(6), 653-657. doi:10.1089/cpb.2008.0088

Starcevic, V., \& Billieux, J. (2017). Does the construct of Internet addiction reflect a single entity or a spectrum of disorders? Clinical Neuropsychiatry, 14(1), 5-10. Retrieved from http:// www.clinicalneuropsychiatry.org/pdf/02Starcevic.pdf

Stavropoulos, V., Alexandraki, K., \& Motti-Stefanidi, F. (2013). Flow and telepresence contributing to Internet abuse: Differences according to gender and age. Computers in Human Behavior, 29(5), 1941-1948. doi:10.1016/j.chb.2013.03.011

Stavropoulos, V., Gentile, D., \& Motti-Stefanidi, F. (2016). A multilevel longitudinal study of adolescent Internet addiction: The role of obsessive-compulsive symptoms and classroom openness to experience. European Journal of Developmental Psychology, 13(1), 99-114. doi:10.1080/ 17405629.2015.1066670
Stavropoulos, V., Gomez, R., Steen, E., Beard, C., Liew, L., \& Griffiths, M. D. (2017). The longitudinal association between anxiety and Internet addiction in adolescence: The moderating effect of classroom extraversion. Journal of Behavioral Addictions, 6(2), 237-247. doi:10.1556/2006.6.2017.026

Stavropoulos, V., Kuss, D. J., Griffiths, M. D., \& Motti-Stefanidi, F. (2016). A longitudinal study of adolescent Internet addiction: The role of conscientiousness and classroom hostility. Journal of Adolescent Research, 31(4), 442-473. doi:10.1177/ 0743558415580163

Stavropoulos, V., Kuss, D. J., Griffiths, M. D., Wilson, P., \& Motti-Stefanidi, F. (2017). MMORPG gaming and hostility predict Internet addiction symptoms in adolescents: An empirical multilevel longitudinal study. Addictive Behaviors, 64, 294-300. doi:10.1016/j.addbeh.2015.09.001

Tsitsika, A., Critselis, E., Kormas, G., Konstantoulaki, E., Constantopoulos, A., \& Kafetzis, D. (2009). Adolescent pornographic Internet site use: A multivariate regression analysis of the predictive factors of use and psychosocial implications. CyberPsychology \& Behavior, 12(5), 545-550. doi:10.1089/cpb.2008.0346

Wanberg, C. R., \& Kammeyer-Mueller, J. D. (2000). Predictors and outcomes of proactivity in the socialization process. Journal of Applied Psychology, 85(3), 373-385. doi:10. 1037/0021-9010.85.3.373

Wolak, J., Mitchell, K., \& Finkelhor, D. (2007). Unwanted and wanted exposure to online pornography in a national sample of youth Internet users. Pediatrics, 119(2), 247-257. doi:10.1542/ peds.2006-1891

Ybarra, M. L., \& Mitchell, K. J. (2005). Exposure to Internet pornography among children and adolescents: A national survey. CyberPsychology \& Behavior, 8(5), 473-486. doi:10.1089/cpb.2005.8.473

Young, K. S. (1998). Internet addiction: The emergence of a new clinical disorder. CyberPsychology \& Behavior, 1(3), 237 244. doi:10.1089/cpb.1998.1.237

Young, K. S., Pistner, M., O’Mara, J., \& Buchanan, J. (1999). Cyber-disorders: The mental health concern for the new millennium. CyberPsychology \& Behavior, 2(5), 475-479. doi:10.1089/cpb.1999.2.475

Young, K. S., \& Rogers, R. C. (1998). The relationship between depression and Internet addiction. Cyberpsychology, Behavior, and Social Networking, 1(1), 25-28. doi:10.1089/ cpb.1998.1.25

Zhou, N., \& Fang, X. Y. (2015). Beyond peer contagion: Unique and interactive effects of multiple peer influences on Internet addiction among Chinese adolescents. Computers in Human Behavior, 50, 231-238. doi:10.1016/j.chb.2015.03.083 